\title{
Siteraturperzeisuis.
}

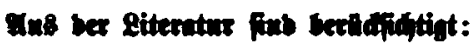

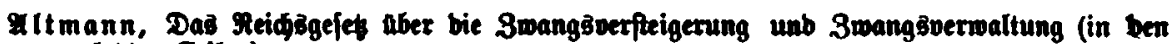
Ieften Selien).

Dabfabner, Die 3wangbolffredung in bab unbeweglide Bermogen.

Das Me ht, heraugigegeben von Dr. \$8. Th. Soergel.

Deut|de Iurtftengeitung, begrinbet von Dr. \$. Labanb, Stenglein unb Staub.

Dernburg, Das OArgerlide Medt.

Fijøer unb Sфaefer, Die Befetgebung, betreffenb bte 3twangövollftrectung in bas unbeweg: lide Bermogen im Meide unb in \$reupen.

Freunb, Die Swangöpolftrecung.

6ruфot Beitrage, Setaug̈gegeben von Maffow, Singet unb Eccius.

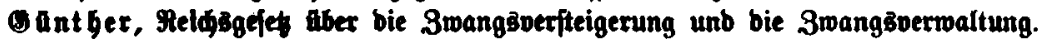

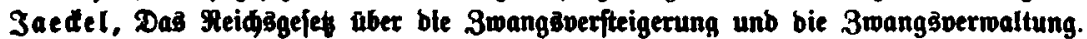

Furlbaum, Reuc Orunbjäłe ber 3wangöverftelgerung (1884).

\&es le, Sergleidjenbe Darftellung bes Pargerlidien Befełbuds.

Peifer, Die 3manglverwaltung in Grunbftidie.

\$land, gargerlides Eefełbud nebft Einfürungsigefes.

Meinharbt, Das 3wangBperfteigerungagefet.

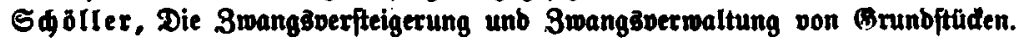

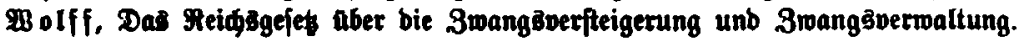

\section{zexiep tigungen.}

Sette 2, Ynm. Betle 9 von oben anftatt "Y6f. 4": "q66f. 5".

Seite 4, Beile 2 von unten binter "unterliegen": "Diefes efe ift burd bas in, jwifben veroffentlide Beles vom 11 . Suni 1902 in ber Faffung vom 8. Juli 1902 abgeånbert, f. S. 318."

Seite 111, 3eile 11 von oben anftatt "für lefteren": "für a noere". Selle 13 von oben anftatt wieber": minber".

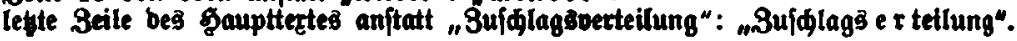

Sette 122, Beile 24 von oben anftatt "engeren": "engen".

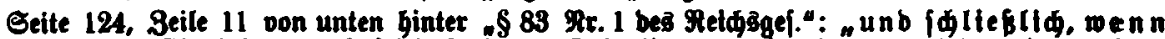
ber Einlettungabefoluß bem Squlbnet abergaupt nidt ober ni申t friftgeredt ougeftellt ift, vgl. S. 95".

Seite 179, in ber zweiten Seile aber und britten Beile unter "QAtteft" anftalt "\$ypotgellen: brief": "Dollft ted baren sitel".

Seite 180, Beile 7 von unten anftalt "Berednung": "Berwagrung".

Seite 188, Seile 12 von oben anftatt "termin": "Derfabren".

Seite 192, Seile 6 von oben anftatt "112": "12".

Seite 201, Inm. 6, 3eile 1 unb 4 von oben anftatt "3 $3 \beta^{\prime \prime}:{ }^{\prime \prime}{ }^{\prime \prime}$.

Seite 216, 3etle 2 von unten anftatt "Eingelgypotbel": "Eingelbypotgeten".

Seite 219, Betle 9 von oben anftatt "verteilen": "erteilen".

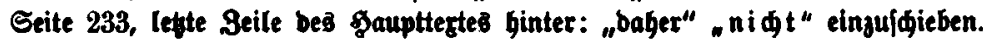

Seite 261, Inm. 6 3elle 7 von oben anftatt "betreibenben": "beitret enben".

Sette 319, Setle 3 von oben anftatt "eingetragenen": "eingetragene".

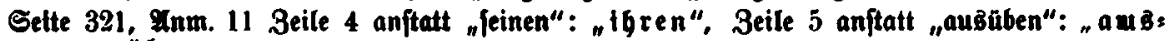
) uี่ 